\title{
LA CULTURE DU CAFÉ AU BRÉSIL.
}

\author{
P A R
}

\author{
M. K. F. VAN DELDEN-LAËRNE.
}

Dans la "Revue Commerciale, Financière et Maritime" de Rio de Janeiro, du 21 juin au 5 juillet 1885 , No. 73, a paru sous le titre sus-mentionné une "Réfutation du Rapport de M. van DeldenLaërne, sur cette culture en Amérique, en Asie et en Afrique."

C'est avec étonnement que j'ai pris connaissance de cet article, car cette... "Réfutation" n'en est pas une, puisqu'elle ne réfute rien!

Il est très concevable que dans un journal comme "Le Brésil ", publié et rédigé à Paris par des Brésiliens qui paraissent être plus versés dans les affaires parisiennes que dans celles de leur propre patrie, - que dans un tel journal, dis-je, les données contenues dans mon rapport officiel soient rendues plus ou moins suspectes, parceque - à tort - on se croit personnellement blessé, ou bien parceque l'assertion que j'avance: "que le travail libre, ne signifie absolument rien pour la culture du café" doit, comme un fait véridique, résonner péniblement aux oreilles de ceux qui semblent avoir pris à tâche d'introduire en Europe des idées contraires.

A de tels articles je pourrais simplement répondre: approfondissez l'étude de mon rapport, car il est évident que les auteurs de ces articles n'ont même pas lu ce rapport!

Le Sieur Oscar d'Araujo, l'auteur de l'article "Pro Patria " dans "Le Brésil" du 23 juillet 1885, reproche vivement au Dr. Ad. Nicolas que ce savant, discutant mon oeuvre dans un estimable article, publié dans "La Liberté " du 7 juillet 1885, dit entre autres:

"L'essentiel est que les esclaves sont, d'après notre auteur, conve"nablement traités au Brésil; les mauvais traitements qu'on a signalés "n'existent qu'à l'état d'exception.

"La pire conséquence de l'état de choses actuel est que l'esclavage "retarde l'immigration des petits travailleurs d'Europe, qui seuls peuvent 
"assurer l'avenir de l'agriculture dans le pays. Au Brésil (Central) "il n'y a, jusqu'à présent, pas trace de travail libre. Tout se fait "par des esclaves."

Il en est tellement blessé, que, profondément indigné, il s'écrie:

"Comment M. Nicolas a-t-il pu se faire l'écho de ces assertions "malveillantes? Pourquoi les déterrer dans un volume que personne "n'a lu (sic), pour leur donner toute publicité dans: "la Liberté?"

De tels journalistes semblent faire partie de cette catégorie de Brésiliens, de ces "filhos da terra", dont je parle dans mon rapport (pag. 104), qui aiment à glorifier leur patrie, en préférant pour eux-mêmes les grandes villes de l'Europe, et qui parlent toujours du Brésil riche et béni, de la terra abençuada, de la filha dilecta do Evangelo, mais qui ne connaissent, de leur immense patrie, que le village ou la fazenda où ils sont nés et.... la rua do Ouvidor de Rio!

Ils se disent "patriotes" - cela pose - et croient aussi agir comme tels, mais hélas! ils font plus de mal que de bien par leurs actes irréfléchis et insensés.

Aussi, c'est à l'égard de tels individus, que le redacteur de la "Revue Comm., Fin. et Marit." dit avec raison, dans son article principal "Le Brésil" inséré dans son numéro du 21 juin 1885 (No. 73):

"Quelles que soient nos opinions au sujet de l'émancipation des "esclaves, nous né pouvons nous empêcher de reconnaître que "cette fâcheuse organisation du travail a retardé... de plus d'un "demi-siècle la formation.... du patriotisme brésilien!"

Eh bien, il se conçoit - dis-je - que de tels journalistes-patriotes désirent rendre suspectes mes données, basées sur des recherches minutieuses et locales.

Mais qu'on puisse, dans une "Revue" rédigée à Rio même par un journaliste qui, je le présume, est ou doit être à même de juger des choses locales, avancer, sous le titre de "Réfutation" de telles balourdises et les amplifier, voilà un fait regrettable et critique.

La rédaction de la "Revue C., F. et M." commence sa "Réfutation" en disant:

"Si nous avions jamais eu des inquiétudes sur l'avenir du café "au Brésil, par suite de la substitution des travailleurs libres aux "esclaves nous aurions été complètement rassurés par la lecture du "volumineux rapport publié par M. van Delden-Laërne, haut fonc"tionnaire du Gouvernement Colonial de Batavia, en exécution de la "mission qui lui avait été confiée, pour aller étudier les causes 
"auxquelles le café du Brésil avait da à l'exposition universelle "d'Amsterdam en 1883 son éclatante réhabilitation et la grande "médaille d'honneur."

Je m'estime très heureux de constater que mon rapport ait pu exercer sur la "Revue" cette influence vraiment rassurante! Il m'est d'autant plus agréable d'apprendre ce fait, que pour moi personnellement, je n'entrevois pas l'avenir de l'agriculture au Brésil en général, dans un horizon aussi sombre que le font beaucoup de Brésiliens, hommes d'Etat distingués.

On n'a qu'à bien lire mon rapport, où je me flatte d'avoir prouvé suffisamment que des Brésiliens, occupant de hautes positions, ressentent plus que moi, - mais contrairement à la "Revue", - des craintes pour l'avenir de la culture dn café au Brésil-Central.

Je fixe spécialement l'attention sur ce qu'a dit, au Sénat et à la Chambre:

10. le Sénateur actuel Moreira de Barras, ancien Ministre des Affaires Etrangères et de l'Agriculture, en ce moment le Chef reconnu des libéraux de la prorince de $\mathbf{S}$. Paulo:

"que l'immigration européenne ne fait pas l'affaire de la "grande "lavoura" (culture du Café), les colons d'Europe désirant travailler "pour leur propre compte et sur leurs propres terres; (tandis que) "l'agriculture existante a besoin de journaliers pour remplacer les "esclaves." (voir page 117 d. m. r.)

"que le gouvernement d'alors, ayant peu d'espoir de saucer la cul"ture du Café par une colonisation européenne, tourna les yeux vers "la Chine, afin de faire venir de là des agriculteurs à bon compte, "en remplacement des esclaves." (voir page $121 \mathrm{~d}$. m. r.)

20. le député Martim Francisco, qui prétend que l'importation des travailleurs chinois est Tunique moyen de sauver la culture du café; sans cela, ce serait.... la banqueroute! Il n'y aurait pas d'autre issue. (voir page $123 \mathrm{~d}$. m. r.)

Eh bien! quelle est ma conclusion?

J'ai dit, voir page 123 d. m. r.:

"S'il en est ainsi, la culture du café y est condamnée.

"Le Chap. III a déjà fait voir que les efforts du Gouvernement "en faveur d'une immigration chinoise ont échoué!"

Cependant, je crois encore fermement, qu'on peut "sauver " la culture du café; qu'il y a une autre "issue" pour éviter la "banqueroute"; car je suis d'avis que: (voir page 331 d. m. r.)

"L'avenir de la Culture du Café au Brésil dépend pour la plus 
"grande partie du pays même. Si l'on se décidait, en sacrifiant beau"coup d'intérêts particuliers, à diviser les grandes exploitations en de "petites parcelles pour les vendre aux colons, je crois fermement "que le courant de l'émigration se dirigerait davantage vers le "Brésil-Central, et que la Culture du Café y regagnerait en impor"tance ce que l'émancipation des esclaves lui aurait fait perdre tem"porairement." .

"Le temps nous apprendra, si cet évènement sera amené à l'ami"able, avant l'émancipation complète des esclaves, ou bien, s'il sera "arraché aux propriétaires par la force de circonstances qu'ils ne "peuvent maîtriser.

"Si le dernier cas arrive, je crains qu'un coup fatal ne soit "porté à la Culture du Café au Brésil, un coup tout aussi décisif "que celui qui a frappé la Jamaïque, par suite de l'émancipation "des esclaves en 1838

"Cependant ce coup ne sera pas irréparable pour le Brésil, comme "il l'a été poưr la Jamaïque; car il ne faut pas oublier, qu'au rebours "de cette île, - qui ne peut, pas plus que l'Inde Néerlandaise, "être colonisée, à cause de son climat, - le Brésil-Central offre par "contre un champ excellent dagriculture aux immigrants d Europe."

"Le changement de la situation agricole amené alors par les cir"constances, ne laisserait pas d'opérer une révolution dans l'agriculture "et dans les rapports économiques généraux, révolution qui pourrait "amener la régénération de la Culture du Café. Tant que la loi "d'émancipation de 1871 restera en vigueur, on ne peut pas s'at"tendre à une diminution notable de la production de Café du Brésil, "dans les 5 à 7 premières années. Cependant il est difficile de pré"dire avec quelque certitude, pour combien de temps l'esclavage four"nira encore un nombre de bras suffisant pour la culture du café."

En comparant la culture actuelle du café au Brésil à celle de la vigne en Australie, la "Revue" prouve qu'elle ne possède que fort peu de connaissances au sujet de l'agriculture tant au Brésil ‘qu'en Australie.

C'est un fait pourtant, que la culture de la vigne en Australie est dirigée par des colons-libres, et cela à leurs risques et périls, sur des terrains qui leur appartiennent; - ce qui constitue justement les conditions de réussite, dont les colons-contractants du Brésil-Central sont privés.

Car, dans les trois provinces du Brésil-Central, où le Café est cultivé, la condition est toute autre! 
Là, le Gouvernement n'a plus de terrains cultivables à vendre (sauf les bens dos conventos, voir page $118 \mathrm{~d}$. m. r.); le tout est entre les mains de grands propriétaires, qui - et c'est là l'unique faute, ne veulent pas avoir de colons-propriétaires sur leurs territoires, mais, ainsi que le dit avec raison le député Martim Francisco, des colons-journatiers "como braço do trabalho, como substituto do braço escravo, como remedio immediato para que a lavoura nāo pereça!" (voir page $123 \mathrm{~d}$. m. r.)

Je le répète, le travail libre, - comme on le comprend - n'existe pas, pour ainsi dire, dans les trois provinces à Café du Brésil. Dans la culture du Café, tout repose sur l'esclavage.

C'est l'esclave qui défriche et qui plante, tandis que le colon ne fait qu'entretenir et cueillir, et ceci n'est encore que parcequ'il ne peut, à aucune autre condition, obtenir des terrains pour y planter des plantes fourragères pour son usage personnel.

Enlevez à la culture du café sa base, c'est-à-dire, émancipez l'esclave, le défricheur et le planteur, vous ne conserverez alors qu'une poignée de quelques milliers de colons, ne s'occupant que de l'entretien de la cueillette.

L'émancipation absolue et subite de l'esclavage doit donc agir d'une manière destructive sur la culture actuelle du café, vu que présentement encore dans les trois provinces à café au Brésil, il n'y a que peu de colons, et que les esclaves devenus libres fourniront sans aucun doute une somme de travail inférieure à celle qu'ils sont obligés de fournir maintenant.

Ce n'est que sur quelques fazendas relativement petites, entre autres sur celle du Major [Novaes, près d'Itatiaïa, - suivant ce que l'on m'a dit, - que l'on a réussi à former les cabocles (indigènes de l'intérieur) à la culture libre du café

Pour la "grande lavoura" cependant, ces faits isolés sont insignifiants, (voir page 243,246 et 319 d. m. r.)

Le Sieur Oscar d'Araujo, qui nomme mes communications, basées sur des études locales "des assertions malveillantes", dit dans "Le Brésil" du 23 juillet 1885 No. 94:

"La vérité est, que méme dans la culture du café, le travailleur "libre prend de plus en plus la place des eselaves.

"C'est ce qu'ont pu constater tous les observateurs impartiaux; "Il n'y a que M. van Delden-Laërne pour le méconnaître." 
Comment, cher patriote! où done sont tous ces mobservateurs impartiaux?" A Paris? peut-être! Au Brésil? non!

J'ai déjà cité plus haut, les assertions (malveillantes?) d'hommes d'état tels que Moreira de Barros et Martim Francisco.

Mon rapport contient en outre des assertions analogues de personnes, qui toutes occupent de hautes positions.

Si les Brésiliens-patriotes, habitant Paris, suivent la marche des événements dans leur patrie, ils se rappelleront sans doute encore les paroles du Sénateur et ancien-ministre-président Martinho Campos, citées dans mon rapport, à la page 67 .

Cet homme politique, qui pendant plus de 25 ans a été le chef et le guide des libéraux au Brésil, déclara dans la Séance du 30 août 1880 :

"Os unicos trabalhadores, pode-se dizer, para o nosso principal "ramo agricola..... sāo os escrpoos! / a

"O trabalho livre, representa uma parte muito insignificante, se nāo... nulla; na cultura do café."

Est-ce assez clair? Eh bien, est-ce que ce témoignage de Martinho Campos est peut-être une "assertion malveillante "? Ou bien, est-il un "observateur partial" comme moi?

Par exemple, est-ce encore une "assertion malveillante, d'un observateur partial", lorsque le Sénateur Moreira de Barros, tant en sa qualité de Ministre, qu'en celle de grand-fazendeiro déclara dans la séance du 3 septembre 1879: (voir note page 121 d. m. r.)

„Considerando que a immigraçāo Europea no Brazil sendo de vantagem.... problematica para a grande lavoura, e nāo apparecido... outro meio de substituir esta estado de difficuldades em que nos achamos, o governo lançou os olhas para esse paiz (China)."

Le député Valladares aurait-il aussi à se reprocher des "assertions malveillantes" lorsque dernièrement encore, dans la séance de la Chambre, le 1 août 1885 , il disait:

que selon lui, l'immigration Européenne est chose de peu d'importance, et que la substitution du travail libre à l'esclavage est une utopie (utopia).

Et pourtant, un grrr... and patriote, comme M. Oscar Araujo, de.... Paris, ose dire:

"Il n'y a que M. van Delden-Laërne qui méconnaisse la vérité: que méme dans la culture du café le travailleur libre prend de plus en plus la place des esclaves!"

En vérité, le député A. d'Escragnolle Taunay, président de la 
province de Paraná depuis le mois d'août 1885, avait bien raison, lorsqu il se prononçait contre le mode de propagande usité en Europe et surtout à Paris, au profit de l'immigration européenne au Brésil.

"L'immigration sur une grande échelle" - disait-il - "restera "impossible tant que le Brésil lui-même continuera à séduire le "monde par des apparences en contradiction avec la réalité, par des " "promessas as mais extraordinarias, enganadores e irrealisaveis" " (voir page 112 d. m. r.)

C'est à de tels efforts de propagande, mal dirigés, que l'on doit attribuer, - et pour cause - la vive opposition de l'Allemagne, de l'Angleterre et de l'Italie.

Pourquoi ne pas être sincère et énumérer, en face des nombreux avantages, les quelques ennuis qui attendent le colon au Brésil?

Celui-ci alors, ne sera pas désillusionné lorsqu'il s'apercevra que le Brésil n'est pas la terre promise, et il n'aura pas lieu de se plaindre et de se croire mystifié, ce qui, malheureusement, arrive assez souvent. (voir page $105-114$ d. m. r.)

A ce sujet, je viens de lire dans un article de M. Eduardo Prado, inséré dans "Le Brésil " du 9 juin 1885 et intitulé: "les colons à Sāo Paulö:

"Il n'y a pas longtemps que des délégations de la colonie italienne de tout le Brésil se sont réunies à $\mathrm{S}$. Paulo. Ce congrès, imposant par le nombre et la qualité des Italiens résidant au Brésil, qui y prirent part, adressa une pétition au Gouvernement de S. M. le roi Humbert, lui demandant.... de lever toutes les entraves opposées à l'immigration au Brésil et, au besoin, de favoriser cette immigration."

Eh bien, toutes ces entraves auraient-elles, sans raison aucune, été opposées à l'immigration italienne au Brésil? (voir page 113 d. m. r.)

La Revue C., F. et M. prouve que le Sieur Oscar d'Araujo est peu à la hauteur des choses au Brésil, lorsque naïvement elle affirme, dans la "réfutation" même de mon rapport;

"Le café du Brésil est aujourd'hui une fois de plus en lutte avec "celui de Java à l'exposition universelle d'Anvers, et si l'opinion "de M. van Delden-Laërne était exacte, nous aurions commencé à "entrer dans la période d'infériorité, car.... depuis deux ans, le tra"vail libre commence à pénétrer dans nos exploitations agricoles."

Si effectivement "le travail libre a commencé, depuis deux ans, à pénétrer dans les exploitations agricoles au Brésil, c'est que cette 
joyeuse nouvelle n'est connue que depuis mon départ de Rio en mars 1884!

A cette assertion de la "Revue" je n'ai rien à ajouter, seulement je désire formellement relever qu'elle n'a pas lu mon rapport ou bien qu'elle l’a fort mal lu, si elle prétend que j'ai dit ou prédit, que: "la culture du café au Brésil commence à entrer dans la période d'infériorité."

Au contraire, j'ai dit, à la page 335 de mon rapport:

"Tant que la loi d'émancipation de 1871 restera en vigueur (et "la nouvelle loi de Saraïva, du 28 septembre 1885 n'y apporte, selon "moi, aucun changement important) on ne peut pas, avant cinq ou "sept années, s'attendre à une diminution notable de la production "de café au Brésil.

La redaction de la "Revue C., F. et M." "ne veut pas prendre "la peine (sic) de réfuter (dans sa "Réfutation") ce qu'il y a d'exagéré "dans les 14 à 15 heures de travail journalier, imposé aux esclaves" et laisse "aux bon sens de nos lecteurs d'Europe le soin de juger "si le travailleur des champs.... en France, en Allemagne, en Bel"gique et en Italie, cherche le repos après 4 ou 5 heures de labeur!"

Je conçois qu'il serait très difficile, sinon impossible à la "Revue" de démontrer que mes communications sont exagérées, lorsque je dis qu'un esclave doit fournir journellement 14 ou 15 heures de travail, affecté exclusivement à la culture du café; - car mes communications sont basées non seulement sur les assertions des personnes les plus compétentes, c'est-à-dire celles des fazendeiros mêmes, mais aussi sur mes études locales.

Ces communications sont en outre confirmées par "la commission d'enquête pour la colonisation de la vallée de Parahyba, en 1884 ", qui dit à cet égard:

"O escravo è empregado em trabalho seguido 14 ou 16 e até.... mesma 18 horas por dia, para beneficiar 3000 à 4000 pés de café" (voir page 80 d. m. r.)

De plus encore, le Sénateur Christiano Ottoni, que la "Revue" voudra bien reconnaître comme une autorité, disait dans son discours, prononcé au Sénat le 9 juin 1884 et inséré dans mon rapport page 80 , ce qui suit:

"Outre les 12 à 14 heures d'un travail pénible, exposés à la "pluie et au soleil, les esclaves durent travailler pendant 2 heures 
"de la nuit, pour préparer la nourriture pour eux-mêmes et pour le bétail, "et le matin pendant une heure, pour nettoyer les séchoirs du café.

"Ce qui fait 15 à 17 heures par jour du travail le plus lourd, "ce qu'aucune constitution ne saurait supporter."

Est-ce assez clair? Cela ne démontre-t-il pas suffisamment, qu'autrefois et actuellement encore, on exige de l'esclave, au moins, 14 à 15 heures de travail par jour?

Cela étant, ma conclusion est-elle donc si inexacte, lorsque je dis que le travail d'un seul esclave, affecté exclusivement à la culture du café, équivaut au labeur de 2 ou 3 colons pour le méme travail?

La "Revue" semble n'avoir qu'une fort médiocre opinion du "bon sens de nos lecteurs d'Europe", si elle ne peut se figurer que ses lecteurs et les miens puissent parfaitement bien comprendre que l'agriculteur Français, Allemand, Belge ou Italien, en venant comme colon-libre en Brésil, $\mathrm{y}$ doit vouer la plus grande partie de son temps à la culture de ses plantes fourragères et à des produits annuels de vente facile, et.... qu'ensuite sculenent il pourra donner un faiblo partie de son temps à la culture du café, culture qui ne devient productrice qu'après 4 ou 5 ans.

Cette faible partie de leur temps, affecté à la seule culture du café, et que j'évalue à 4 ou 5 heures par jour, opposée au 14 ou 15 heures par jour que l'esclave est obligé de donner à la méme culture, au profit du maître qui le nourrit et l'abrite, me fait dire à la page 330 de mon rapport:

"Il ne suffirait nullement de mettre un colon à la place de chaque esclave qui serait perdu pour la culture; ces 284 mille esclaves, travaillant exclusivement à la culture du café pendant 14 à 15 heures au moins par jour, représentent la force de travail de 700 à 800 mille colons, qui certes ne pourraient donner tout au plus que 4 ou 5 heures par jour au méme travail."

La "Revue" n'est pas de bonne foi, lorsqu'elle supprime le mot méme, en citant ce que j'ai dit!

Dàns le Brésil-Central, le colon européen libre n'a pas besoin de prendre du repos après 4 ou 5 heures de travail; il peut travailler presque le double de ce laps de temps, mais.... il ne le fera pas, pour le méme travail que celui de l'esclave, c. à d. temps exclusivement voué à la culture du café, pour le compte.... d'autrui.

De deux choses l'une. 
Ou la "Revue" semble être peu versée dans les affaires intérieures du Brésil, en particulier dans celles des régions à café que j’ai parcourues en tout sens, ou bien elle a lu mon rapport d'une manière très superficielle.

En admettant que cette dernière hypothèse soit la vraie, je prends la liberté de lui donner le conseil de ne plus se conduire, dorénavant, d'une manière si... puérile, car je considère comme très puéril de dire:

"Si nous avions jamais eu des inquiétudes sur l'avenir du café "au Brésil, pour cause de la substitution des esclaves par des travait"leurs libres, nous aurions été complètement rassurés par la lecture du volumineux rapport publié par M. van Delden-Laërne."

Après avoir déclaré, dans un leading-article du même numéro, sous le titre de "Le Brésil, article pour nos confrères d'Europe."

"Entre le Gouvernement et la Nation, il y a l'aveu d'une néces/sité nouvelle.

"Les uns et les autres, dans une mesure différente, sentent que "l'heure est venue de procéder à une sorte d'épuration du passé, "de liquidation morale et matérielle"......

"Tout compte fait, les esprits oscillent incessamment entre des "courants contraires, sans parvenir à se fixer.

"L'abolition de l'esclavage, sous quelque forme qu'on la présente, "compromet trop de positions acquises, met en lutte trop de passions "et d'intérêts pour que l'on puisse compter sur une de ces périodes "de confiance, dont on a joui dans d'autres temps.

- "On n’a qu'une.... confiance à court délai, on ne se flatte pas "de longues perspectives, et on ne se laisse aller à l'espérance.... "qu'avec une certaine disposition à s'inquiéter de tout, en se tenant "aux aguets et en s'attendant toujours à l'imprévu.

"Il faut en prendre son parti et s'aguerrir..... contre ces per"plexités. "

D'accord! seulement, selon moi, on ne s'aguerrit pas contre ces "perplexités", en disant au pauvre monde, qu'on n'a "jamais eu des "inquiétudes sur l'avenir du café au Brésil par suite de la substi"tution des travailleurs libres aux esclaves."

Je termine enfin en citant les mots remarquables du député conservateur de S. Paulo, le Sieur Antonio Prado (propriétaire de la fazenda Santa-Vérédiana, voir page $316-317$ d. m. r.) et Ministre de l'Agriculture depuis le 20 août 1885, qui dernièrement encore, 


\section{VAN DELdEN-LAËrNe, LA CULTURE dU CAFÉ AU BRÉSIL.}

c. à d. dans la séance de la Chambre, du 1 juillet 1885, disait entre autres:

"Comment, Messieurs, peut-on douter (duvidar) que le Brésil se "trouve présentement dans de telles conditions, surtout quand on "fait attention au cadre dans lequel se projettent: o estado angus"tioso da nossa lavoura, le décroissement de la rente, la baisse des "fonds publics, la dépréciation de nos principaux produits agricoles, "la disproportion entre les recettes et les dépenses, les déficits qui "s'accumulent annuellement, et, comme conséquence de tout cela, "o abatimento do espirito publico, qui commence à perdre la con"fiance que lui inspiraient les institutions qui nous gouverment!"

Est-ce que tout cela ne serait qu'une illusion de notre esprit, que la conséquence de l'alarme de notre patriotisme?

Por certo que $n^{t_{0}}$ ! Ce que nous observons dans ce cadre, est....... a triste reatidade! (voir Jornal do Commercio. Rio de Janeiro. 12 de Julho 1885).

Ile de Java,

Le 2 décembre 1885 . 